\title{
PROFESSORA OUVINTE NA EDUCAÇÃO DE SURDOS: DIÁLOGOS SOBRE HISTÓRIAS E BRINCADEIRAS NA EDUCAÇÃO INFANTIL
}

\section{LISTENING TEACHER IN THE DEAF EDUCATION: DIALOGUES ABOUT STORIES AND PLAY IN CHILD EDUCATION}

\author{
Claudia Pimentel ${ }^{45}$ \\ Keissy Sibelly Morais Limite ${ }^{46}$ \\ Vivian Buenaga de Azevedo ${ }^{47}$
}

\begin{abstract}
Resumo
O objetivo deste trabalho é destacar a importância da construção de materiais didáticos para a educação infantil que favoreçam a experiência visual das crianças surdas, através de objetos que agucem a curiosidade na medida em que se relacionam às revistas, narrativas, aos livros e brincadeiras cantadas, presentes no contexto infantil. Partimos da premissa que a linguagem não é um produto acabado, mas que está em permanente processo de produção e é possível percebê-la nas mais diversas formas de comunicação e expressão. A metodologia escolhida foi a análise de materiais construídos, contextualizando-os com as propostas de leitura e jogos corporais. Os resultados apontam para uma maior comunicação quando os materiais expressam autoria e permitem que as crianças se identifiquem com o processo de produção.
\end{abstract}

Palavras-chave: Educação infantil. Língua de sinais. Leitura compartilhada. Brincadeira.

\section{Abstract}

The objective of this work is to highlight the importance of building didactic materials for early childhood education that favor the visual experience of deaf children, through objects that excite curiosity as they relate, narratives, to books and sung games present in the children's context. We start from the premise that language is not a finished product, but that it is in a permanent production process and it is possible to perceive it in the most diverse forms of communication and expression The chosen methodology was the analysis of constructed materials, contextualizing them with the proposals reading and body games. The results point to greater communication when the materials express authorship and allow children to identify with the production process. Keywords: Children school. Sign language. Shared reading. Play.

\footnotetext{
45 Professora do Programa de Pós graduação em Educação Bilíngue do Instituto Nacional de Educação de Surdos.

46 Pedagoga. Educação Bilíngue. Mestranda do Programa de Pós graduação em Educação Bilíngue do Instituto Nacional de Educação de Surdos. E-mail: sibellylimite@gmail.com. Telefone: (22) 998893172.

${ }^{47}$ Mestranda do Programa de Pós graduação em Educação Bilíngue do Instituto Nacional de Educação de Surdos.
} 


\section{RevistAleph}

\section{Introdução}

O campo da educação de surdos é um convite à reflexão sobre a visualidade, dada a centralidade da língua de sinais - gesto visual. O objetivo deste trabalho é destacar a importância da construção de materiais didáticos para a educação infantil que favoreçam a experiência visual das crianças, através de objetos que agucem a curiosidade na medida em que se relacionam as narrativas, livros, brincadeiras e poemas presentes no contexto infantil. Trazemos a análise da produção de atividades do contexto ouvinte adaptadas para o contexto de alunos surdos, bem como sua execução, sendo fruto de um projeto de pesquisa de práticas pedagógicas para o contexto do bilinguismo.

Tomando como referência a pesquisa de Campello (2008), percebe-se que a língua de sinais não se resume aos signos-sinais, pois pressupõe a expressão corporal, facial e outros recursos perceptíveis visualmente. Segundo a autora, os "aspectos da visualidade na educação de Surdos tem que estar relacionada com o seu mundo e sua experiência visual desde a educação infantil" (p. 135). Entendemos que a visualidade está presente nos espaços e nos objetos e que a infância é tempo da experiência e não de aprendizagens baseadas apenas em conceitos. Aquilo que cerca as crianças e que está diante dos seus olhos ganha uma importância ainda maior quando se pensa a educação de surdos:

As técnicas, recursos e perspectivas utilizados nos aspectos da visualidade na educação de Surdos, estão relacionados com o uso da "visão", em vez da "audição", sendo que a imagem na "apreensão do estímulo visual" e perspectiva emergem de acordo com forças bidimensionais e tridimensionais. Esses processos exigem uma nova forma de pensar o nível perceptivo e o processamento visual daquilo que rodeia o sujeito Surdo e qual seu olhar sobre o mundo no processo de ensinar e aprender (CAMPELLO, 2008, p. 136).

Autores como Karnopp (2001), Lebedeff (2007), Taveira (2014) entre outros, apontam que, na escola inclusiva para surdos, nem sempre a língua de sinais é aceita, principalmente em atividades relacionadas ao letramento e à chamada "contação de 


\section{RevistAleph}

histórias" ou leitura compartilhada. A língua de sinais, mesmo nos anos iniciais da educação básica, na maioria das vezes é empregada para dar destaque à língua portuguesa escrita, não sendo percebida, em inúmeras experiências pedagógicas, como suficiente para a construção de sentidos e práticas de linguagem. A esta perspectiva que revela a hegemonia da língua portuguesa escrita e sua presença majoritária nas escolas soma-se o fato de que $95 \%$ das crianças surdas são filhas de pais ouvintes (KARNOPP, 2001) o que reforça a ausência da língua de sinais para muitas crianças surdas durante um período significativo para a constituição de identidade e de exploração do mundo. No entanto, de acordo com a legislação atual, as crianças surdas têm direito ao acesso à língua visual espacial, principalmente em suas atividades rotineiras como brincadeiras, histórias, passeios e atividades diversas. As crianças surdas têm direito a estabelecer relações afetivas e de aprendizagem em Libras, de forma a perceber usos e funções da linguagem na escola, principalmente aquelas que não têm esse acesso em casa para que não enfrentem consequências em função da aquisição tardia de uma língua.

Muitos pesquisadores defendem que na escola de educação infantil as crianças surdas devem ter professores surdos, que garantam o acesso à língua de sinais fluente e modos de ser e de estar associados à identidade surda. Ao contrário das crianças ouvintes que têm mais probabilidade de desenvolver fluência conversacional em sua língua nativa desde os primeiros anos de vida, tanto no ambiente da família como em creches $^{48}$, as crianças surdas que nascem em famílias de ouvintes são tradicionalmente ensinadas a aprender a estrutura linguística da língua oral ainda que tenham, com muita sorte, acesso à língua de sinais em casa. Os professores surdos garantiriam a inversão dessa lógica, dando a oportunidade de as crianças surdas terem acesso imediato à língua de sinais.

Os estudos de Taveira (2014) nos levam a considerar a formação dos professores surdos, pois muitas vezes estão nas escolas como instrutores:

com mais ênfase, verificamos os imperativos de transformarmos os Instrutores Surdos em Educadores Surdos, proporcionando-os

\footnotetext{
${ }^{48}$ Segundo as Diretrizes Curriculares Nacionais para a Educação Infantil (BRASIL, 2010), a educação infantil se divide em creches (atendimento às crianças de zero a três anos de idade) e pré-escola (atendimento às crianças de 4 a 6 anos de idade, conforme mês de aniversário).
} 


\section{RevistAleph}

contratação justa e a possibilidade de concurso público na rede municipal, pois eles têm como diferencial um conjunto de ações em sua prática pedagógica que revelam a busca de uma didática diferenciada, uma didática da invenção surda, em que o letramento visual ocupa lugar central (TAVEIRA, 2014, p.64).

Um olhar atento para a "didática da invenção surda" destacada por Taveira (2014) aponta caminhos para pensar a formação de professores surdos ou ouvintes para além dos limites da linguística, tendo em vista vários aspectos, inclusive a rotina, o currículo e no caso da educação infantil atividades como brincadeiras e leituras literárias que ganham mais visibilidade e compreensão das crianças, surdas e ouvintes, quando são apresentadas com elementos lúdicos, miniaturas e objetos do cotidiano que se relacionam com os contextos das práticas e estratégias didáticas.

A importância do acesso a uma língua ainda na primeira infância justifica-se porque a língua, como uma construção histórica e social, é um patrimônio que deve ser garantido a todos. Contudo, o foco exclusivo na língua pode deixar de lado seus usos e funções, e as diferentes formas de manifestação de afetividade e de empatia. Saber uma língua não garante interações. É preciso sustentar a aprendizagem da língua sem perder de vista a dimensão da linguagem:

Autores como Vygotsky, Bakhtin e Benjamin fundamentam novos olhares para o sujeito com base na cultura, na história e na vida social. O objeto de estudo, que antes era a língua, passa a ser também a linguagem, a interação verbal, e as concepções de linguagem que sustentam as práticas. Aspectos como a atividade simbólica, a função dos signos e a questão da ideologia ganham relevância em estudos que tomam a linguagem como constitutiva do sujeito. Para Vygotsky (1989), por exemplo, o jogo, o desenho e a escrita têm a mesma base, pois são atividades simbólicas, que se desenvolvem a partir do esforço da criança para se distanciar da sua percepção imediata dos objetos, buscando abstrair e pensar através dos sentidos e dos significados compartilhados nas relações interpessoais (PIMENTEL, 2011, p. 32).

Nas interações com as crianças, o corpo sinalizante ganha importância e a atenção às reações e respostas das crianças também. Tatiana Lebedeff (2007) 


\section{RevistAleph}

apresenta, em artigo publicado pela ANPED ${ }^{49}$, a proposta de leitura compartilhada ${ }^{50} \mathrm{da}$ escola americana Gallaudet ${ }^{51}$, referência na educação de surdos. Segundo Lebedeff, essa proposta faz parte da formação direcionada aos pais e familiares ouvintes de crianças surdas.

A proposta de leitura compartilhada de Gallaudet se baseia em 15 princípios, que buscam garantir a compreensão das crianças sobre o que está sendo proporcionado a elas no momento da leitura. A leitura é feita em língua de sinais, mas não há obrigação de tradução de todas as palavras em sinais nem de explicação de todos os conceitos de uma vez, pois é importante que se repita a experiência com o mesmo livro sempre que o interesse da criança for percebido, sendo facultado o direito de pular páginas ou abandonar o livro de acordo com o desejo da criança. Ainda que seja possível adaptar a narrativa à capacidade de compreensão da criança, é importante que o adulto se esforce para fazê-la compreender através de explicações paralelas e outros recursos tais como mostrar objetos e proporcionar-lhe experimentações. "Para que a história seja mais compreensível para a criança, (...) aos poucos, ao perceber que a criança realmente compreendeu o foco da narrativa, o leitor, lentamente, deverá focalizar mais e mais no texto" (LEBEDEFF, 2007).

Acionar as experiências já vividas pelas crianças é relevante, de forma que se percebe que na proposta de leitura compartilhada de Gallaudet a interação adultocriança é considerada de fato uma via de mão dupla. Um dos princípios que explicita a importância da troca dialógica com a criança sugere: "Usar o contato visual para convocar a participação da criança. Olhar a criança ao ler, comunicar-se com o olhar, convocar a participação com o olhar que pode ser questionador, exclamativo, entre outros." (LEBEDEFF, 2007). Percebe-se a importância de contar histórias em língua de sinais sem perder de vista o livro, as interações e principalmente o interesse das crianças.

Os 15 princípios da leitura compartilhada de Gallaudet têm sido inspiração para outras propostas pedagógicas. A dialogia proposta pelo método de leitura

\footnotetext{
${ }^{49}$ Anped - Associação Nacional de Pós-Graduação e Pesquisa em Educação. Ver https://anped.org.br/

${ }^{50}$ Ver: https://www3.gallaudet.edu/clerc-center/our-resources/shared-reading-project.html

${ }^{51}$ Ver: https://www.gallaudet.edu/
} 


\section{RevistAleph}

compartilhada pode ser apropriada em outras iniciativas uma vez que vem ao encontro dos eixos do currículo propostos pelas Diretrizes Curriculares Nacionais da Educação Infantil - DCNEI- (BRASIL, 2010). Esse documento indica que "as práticas pedagógicas que compõem a proposta curricular da Educação Infantil devem ter como eixos norteadores as interações e a brincadeira" (p. 25), sendo o currículo baseado em experiências que ofereçam às crianças oportunidades de atribuir um sentido pessoal aos saberes e conhecimentos que vão sendo articulados e construídos a partir do acesso aos patrimônios da humanidade e aos saberes socialmente valorizados. A centralidade dos sentidos atribuídos pelas crianças na experiência com a cultura é, portanto, um eixo norteador do trabalho e que pode ser percebido também nos 15 princípios da proposta de leitura compartilhada.

Essas reflexões sobre currículo na educação infantil são pertinentes, pois os princípios da leitura compartilhada podem ser adaptados para o ensino de jogos, brincadeiras e outras atividades da rotina das crianças na educação infantil. Usar a língua de sinais, acompanhar o interesse das crianças, monitorar se estão compreendendo os conceitos utilizados, usar diferentes estratégias para ampliar a construção de sentidos são algumas atitudes desejadas em professores, surdos ou ouvintes, que trabalhem com crianças, surdas ou ouvintes, tendo em vista o "como fazer", tão bem proposto pela metodologia da leitura compartilhada. À noção de um currículo construído para que as crianças tenham uma experiência cultural diversificada acrescenta-se um método de interação que monitora, valoriza e respeita o interesse da criança.

A experiência vivida por uma criança ativa que traz sentimentos, desejos, observações nas relações entre pares e com professores na escola inclui a língua, mas envolve aspectos de linguagem, afetividade e expressão, externados por todo o corpo e mente através de ações e interações. Essa criança ativa é definida nas Diretrizes Curriculares Nacionais para a Educação Infantil como:

Sujeito histórico e de direitos que, nas interações, relações e práticas cotidianas que vivencia, constrói sua identidade pessoal e coletiva, brinca, imagina, fantasia, deseja, aprende, observa, experimenta, narra, questiona e constrói sentidos sobre a natureza e a sociedade, produzindo cultura (BRASIL, 2010, p. 12). 


\section{RevistAleph}

Cabe lembrar que os estudos sobre a língua de sinais e sua identidade gesto visual têm ampliado o olhar para aspectos relevantes tais como as expressões faciais e corporais que podem ser gramaticais ou não. A dimensão expressiva do corpo e dos gestos tem lugar especial nas considerações sobre a leitura e as brincadeiras com as crianças. Abrahão (2020) explicita em seu estudo que as poesias são apresentadas em performances variadas:

Observando a estrutura superficial dessas poesias apresentada no SLAM surdo, podemos dividi-las em duas categorias, aquelas que utilizam a estrutura gramatical das línguas de sinais, isto é, poesias com narrativas compostas por sinais e itens gramaticais próprios da língua, como a poesia Empatia do grupo Slam do Corpo. E a segunda categoria, com poesias compostas apenas por classificadores, sem a utilização de nenhum sinal como, por exemplo, Symbiosis. Porém existem outras características presentes nas duas categorias e que dão o formato final da obra como a rima, expressões facial/ corporal, ritmo, métrica, som, movimento e velocidade (ABRAHÃO, 2020, p. 40).

O autor acrescenta que "no Visual Vernacular o uso de classificadores, da linguagem cinematográfica, de mímica e expressões faciais fornecem pistas importantes para pessoas que não sinalizam terem compreensão e serem afetados pela mensagem de forma singular" (ABRAHÃO, 2020, p. 47). O uso de classificadores é uma constante na expressividade dos sujeitos que usam a língua de sinais. São gestos que intensificam sinais e que muitas vezes são de conhecimento geral ou de grupos regionais. Os elementos expressivos associados aos sinais e que se manifestam através do corpo, do olhar, da expressão facial, da movimentação corporal como um todo e de elementos que indicam velocidade, acordo, desacordo revelam que a comunicação se dá na interação entre sujeitos que comunicam não só sinais, mas desejos, sentimentos. Esse fenômeno não é exclusivo da língua de sinais. Como afirma Bakhtin citando Voloshinov,

Na realidade não são palavras o que pronunciamos ou escutamos, mas verdades ou mentiras, coisas boas ou más, importantes ou triviais, agradáveis ou desagradáveis, etc. A palavra está sempre carregada de um conteúdo ou de um sentido ideológico [ideologia formalizada] ou vivencial [ideologia do cotidiano] (VOLOSHINOV, 1986, p. 95, grifos do autor). 


\section{RevistAleph}

É apostando na aproximação de diferentes estudos relacionados ao currículo da educação infantil e da educação de surdos que se compreende que professores ouvintes podem oferecer subsídios para a didática necessária nas práticas de inclusão de surdos. Na intenção de contribuir para os estudos sobre o currículo na educação infantil de surdos, apresentamos a seguir duas propostas: uma para leitura compartilhada (contação ou libração de histórias) e uma para jogos e brincadeiras adaptadas do repertório tradicional da cultura brasileira para crianças surdas.

\section{Metodologia}

Como estratégia metodológica, optou-se pela construção e análise dos materiais adaptados, contextualizando-os em propostas de leituras de livros, brincadeiras e jogos corporais. A justificativa desse estudo é a necessidade de novas metodologias de ensino, específicas para educação de surdos, as quais se comunicam diretamente com a cultura deste povo, contrapondo os velhos métodos e metodologias aplicadas de maneira generalizada. Bem como a valorização da produção artesanal do

professor, necessária para que os objetos e artefatos didáticos componham a experiência imediata das crianças, personalizando a relação de ensino-aprendizagem e descartando modelos estereotipados distantes das vivências e das relações das crianças. As reflexões aqui apresentadas se inserem no campo da Educação Infantil, primeira etapa da Educação Básica, conforme definições das Diretrizes Curriculares Nacionais para a Educação Infantil (BRASIL, 2010). O eixo que sustenta a argumentação é a afetividade presente nas relações interpessoais na construção de uma pedagogia da infância que pense a inclusão de crianças surdas pelos saberes e metodologias de proposta didáticas, num possível currículo da Educação Infantil. A hipótese é que haja na didática própria da educação infantil algo a acrescentar à importância do uso da língua de sinais na educação de surdos e que possa ser percebida no uso de objetos tradicionais como bonecos, cartazes e também mídias contemporâneas como o uso de vídeos para registros de histórias e brincadeiras. 


\section{RevistAleph}

\section{Resultados e Discussões}

Em contextos de inclusão nos quais o professor é ouvinte e o aluno é surdo, temos o impasse da diferença linguística, porém, com os conhecimentos básicos de Libras adquiridos em sua formação, o docente pode elaborar materiais adaptados e buscar estabelecer uma interação com esse aluno através do uso de classificadores, sinais básicos, gestos, mímicas, expressões corporais e faciais: o mais importante é fazer com que o aluno sinta-se amado, incluído e respeitado. A formação docente caminha para alcançar os pressupostos do Decreto 10.502 de setembro de 2020, que estabelece em seu artigo 8o que um dos atores da prestação de serviço da educação especial são "professores bilíngues em Libras e língua portuguesa". (BRASIL, art. 8o, inciso III) ou seja, a fluência em Libras passa a ser requisito importante para os professores que atuam com crianças surdas.

Pensando nessas variações de linguagem, estabelecemos uma pesquisa para o aprofundamento de questões sobre a Libração de histórias para crianças pequenas, como ferramenta de inclusão, ensino e principalmente ludicidade. Definimos o termo Libração como o ato de contar histórias em Libras. O termo segue o mesmo processo de formação de palavras da palavra Contação, que parte do verbo contar acrescido do sufixo de ação "ção". Consideramos librar como verbo e acrescentamos o mesmo sufixo de ação, para formarmos o termo Libração.

O momento da Libração de histórias é rico para o trabalho do professor, mas deve ser planejado com o foco principal de despertar o prazer na criança, promovendo o contato com sua língua favorecendo a exploração da leitura de forma descontraída e livre de cobranças. As crianças naturalmente têm no adulto seu referencial, para as crianças surdas, o adulto sinalizante torna-se seu modelo também no que se refere a língua. Ao colocar-se como contador da história o docente a introduz no contexto da narrativa.

Quando há o incentivo docente para o aluno externar seus pensamentos, ele coloca-o na posição de contador, criador de conteúdo. Sobre a riqueza dessa prática, 


\section{RevistAleph}

Delmar (2016) esclarece alguns dos benefícios e possibilidades que surgem através deste reconto de histórias:

Assim que a criança se põe como contadora da história ela se apodera do discurso, ela se torna livre para criar e brincar com a história que à ela foi contada. Esse é o momento de avaliar o desenvolvimento linguístico da criança, a fluidez de sua sinalização, os sinais novos adquiridos, se são sinais complexos ou não, se compreendeu a sequência da história, entre outras (DELMAR, 2016, p. 31).

Além dessas observações que a autora citou, o incentivo do professor quanto a comunicação livre da criança mostra que mesmo que ela não tenha fluidez na sinalização caso ela consiga expressar-se fazendo-se compreender é um avanço importante e um ponto a ser valorizado. O contato direto com os livros, mesmo aqueles com escrita em português, também incentiva esse processo, pois através das figuras o aluno pode contar a história à sua maneira. Pimentel (2011) em seus estudos destaca que

considerar o que as crianças fazem quando estão com os livros pode ser uma estratégia de legitimar certos caminhos da aprendizagem, por um lado, e, por outro, redimensionar os papéis do professor, da didática e da pedagogia Nesse sentido, antes de afirmar que as crianças estavam brincando de ler, melhor seria afirmar que uma das formas de aprenderem a ler é lendo, explorando livros, conversando sobre as possibilidades de leitura (PIMENTEL, 2011, p. 50).

A autora acrescenta a importância de valorizar as ilustrações dos livros, sendo "preciso considerar que ler imagem não é necessariamente outro procedimento para a aprendizagem da leitura, pois é um exercício de verbalização e de discursividade." (PIMENTEL, 2011, p.50). Esse processo do discurso vai além da decodificação da língua, aborda questões de compreensão e interpretação de contextos, tão importantes quanto a fluência linguística.

Portanto, os livros, a Libração de histórias e o contador são partes da formação do sujeito surdo, com papéis distintos, mas complementares. O contato com a literatura literária promove um conhecimento de mundo único, numa experiência individual, mas ao mesmo tempo cultural, social e rica em historicidade. Para os surdos, esses momentos permitem a ampliação do conhecimento tanto sobre a cultura ouvinte, 


\section{RevistAleph}

quanto a cultura surda, no caso da literatura surda; além de ressignificar esses saberes de acordo com suas vivências. Mourão (2016) traz a seguinte reflexão:

Afinal, quando se recebem os conhecimentos na escola e/ou circulam na comunidade, tal como em formas de contação de histórias e leituras dos livros, os sujeitos adquirem e produzem conhecimentos, são subjetivados por sistemas de representação, construindo suas práticas discursivas (MOURÃO, 2016, p. 38).

Tomemos como exemplo a elaboração do vídeo ${ }^{52}$ com a Libração da história "O domador de monstros" escrita pela autora Ana Maria Machado (2003). Como recurso inicial usamos o livro desta história que foi escrita em língua portuguesa e ilustrada por Suppa, com imagens coloridas e um total de 31 páginas. Consideramos essa narrativa como parte da Literatura Ouvinte e para usarmos com um público surdo foi necessário inseri-la em uma modalidade da Literatura Surda (Mourão, 2016). Escolhemos a modalidade da Tradução que consiste em traduzir o texto para a Libras sem modificar o contexto nem os personagens, mas realizando algumas adaptações.

A narrativa gira em torno do personagem Sérgio, um menino que tinha medo do escuro e que em uma noite começa a olhar o movimento das árvores pela janela do seu quarto e imagina alguns monstros. Sérgio conversa com os monstros pedindo para irem embora, mas como eles sempre se recusam, ele chama um monstro ainda mais feio para assustá-los. No final, o menino acaba achando os monstros engraçados e cai na gargalhada fazendo com que seu medo vá embora (MACHADO, 2003). É uma narrativa divertida que mexe com a imaginação das crianças, com um contexto que muitas se identificam. Originalmente aparecem oito monstros na história, mas para encurtar um pouco e para os efeitos dessa pesquisa, mantivemos as características dos monstros dividindo-as apenas em três monstros. Ao todo usamos quatro personagens na nossa história, sendo o Sérgio e mais três monstros.

Inicialmente, na fase de Pré-produção, foi feito um estudo do contexto da narrativa, do ambiente, dos personagens, da mensagem passada, do interesse para os espectadores e dos recursos a serem utilizados. Resolvemos elaborar três recursos

\footnotetext{
${ }^{52}$ Assista ao vídeo através do link: https://youtu.be/iHdqODDIDV4
} 


\section{RevistAleph}

diferentes para a Libração desta história: um curta-metragem em Libras gravado pela pesquisadora; uma Oficina de Libração junto aos alunos, e uma Contação da história pelos próprios alunos.

Foram confeccionados fantoches de pratos de papelão com os seguintes objetivos: auxiliar no conto da história, chamar a atenção das crianças, servir como recurso visual, despertar a imaginação da plateia, permitir o manuseio dos discentes. Os pratos de papelão foram pintados com tinta de tecido e as partes de seus rostos e corpos foram confeccionadas com recortes de papel colorido e coladas com cola permanente. Veja a seguir o resultado (Figura 1):

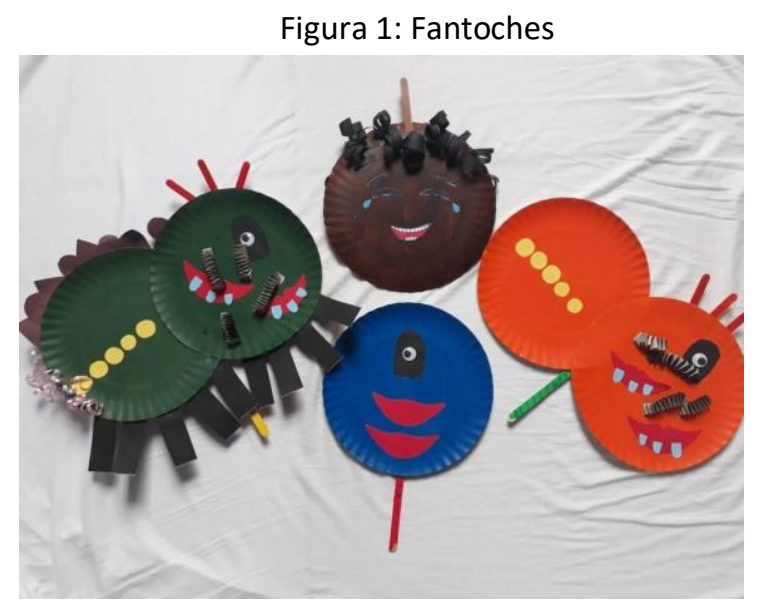

Fonte: Propriedade dos autores.

Cabe destacar que o personagem Sérgio, no início do livro, é um menino assustado e com medo, mas no final ele acaba achando os monstros engraçados deixando o medo ir embora. Foram confeccionados dois fantoches do menino com expressões faciais diferentes para representar essa mudança de humor. Aproveitando o mesmo prato de papelão, de um lado vemos o Sérgio assustado e do outro o Sérgio sorridente (Figuras 2 e 3 ).

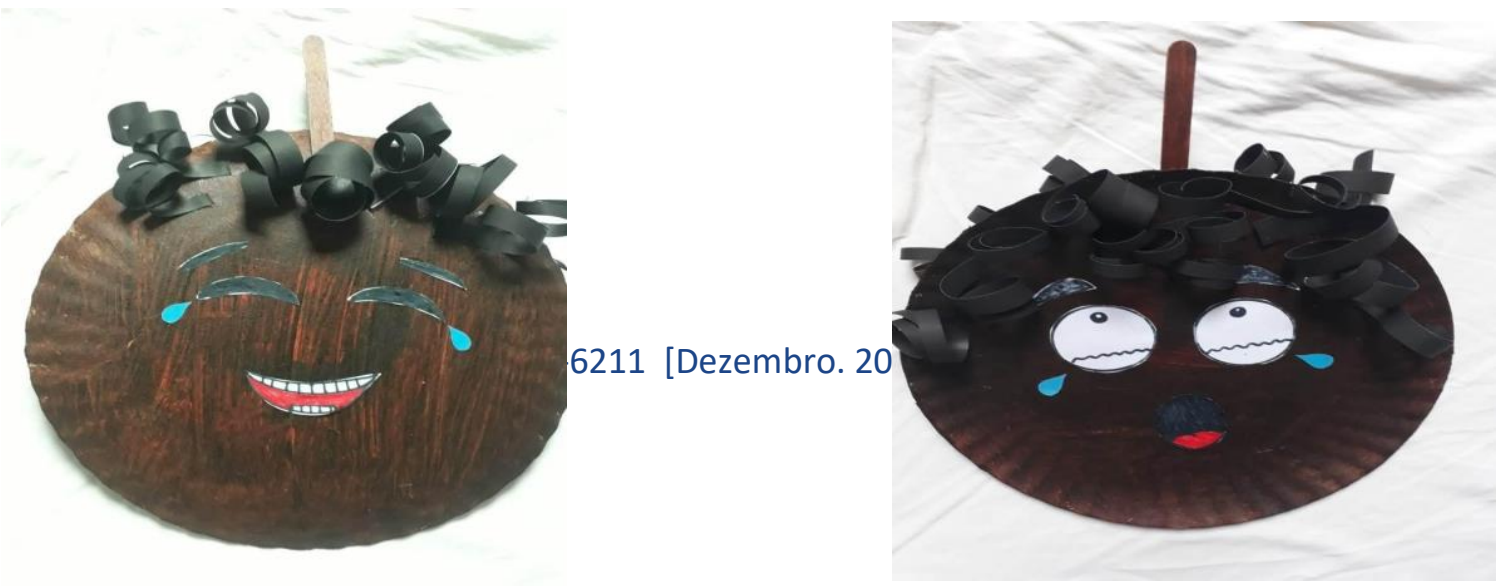




\section{RevistAleph}

Fonte: Figuras 2 e 3 - Propriedade dos autores.

Após essas etapas, foram elaborados roteiros literário ${ }^{53}$ e técnico ${ }^{54}$ para a gravação do vídeo, levando-se em consideração: a luz do ambiente, o enquadramento, o cenário, a distância e a altura da câmera, o posicionamento do sinalizante, o vestuário, a clareza dos sinais. Em seguida, foram gravadas as cenas através de um smartphone. Posteriormente, na etapa de Pós-produção o curta-metragem foi editado em aplicativo de edição de vídeo, quando inseriu-se a legenda em português, o som ambiente foi retirado, foram feitas as montagens, cortes e ajustes. Ao assistirem o vídeo, as crianças identificaram a professora, o que gerou empatia e desejo de sinalizar a história também. A professora realizou o reconto junto com as crianças usando os bonecos e em seguida, elas posicionaram-se como contadoras da história, expressando sua visão da narrativa, sinalizando, e comunicando-se com os colegas. Essa empatia é o objetivo principal da criação desses artefatos.

Esse é um dos recursos que pode ajudar a estabelecer uma comunicação entre surdos e ouvintes em ambiente bilíngue, buscando superar os desafios dessa realidade. A libração de narrativas literárias amplia o conhecimento de glossários de sinais de uso cotidiano, bem como de seus sentidos usuais. Para além da fluência linguística, valorizamos também o esforço do docente ouvinte em inserir-se na comunidade surda de modo a acrescentar experiências positivas na vida de seus alunos surdos

As brincadeiras cantadas (com versos e brincadeiras com as palavras/sinais) trazem a dimensão da língua - são brincadeiras que brincam também com a linguagem verbal, o que as aproximam das narrativas literárias. Contudo, espera-se que as crianças façam movimentos, imitem gestos, utilizem a expressão corporal e estejam ativas, no sentido do desenvolver sua psicomotricidade durante as brincadeiras cantadas. Foi

\footnotetext{
53 Organização em sequência dos elementos textuais.

${ }^{54}$ Definição de elementos técnicos e gráficos para as cenas, exemplo: posição do sinalizante, dos móveis...
} 


\section{RevistAleph}

interesse da pesquisa perceber como a construção de materiais didáticos favorecem também as atividades relacionadas à educação física na primeira infância. Há uma diferença na rotina da educação física e na sessão de leitura compartilhada, relacionada ao objetivo básico de desenvolvimento da psicomotricidade.

O levantamento na literatura sobre a inclusão do aluno surdo nas aulas de educação física escolar justifica a necessidade de o professor de educação física buscar habilidades técnicas para trabalhar com a comunidade surda. Por ter a educação física um caráter motivador e criativo, faz com que, principalmente a criança, torne-se mais ativa e interessada e é neste jogo de motivação, aprendizagem e troca de relações tanto internas quanto externas, que se evidencia um processo de comunicação constante entre ela e o meio que a cerca. Ao se propor esta relação entre educação física e comunicação, compreende-se que ambas são de extrema importância para o desenvolvimento do ser humano, é natural, portanto, buscarmos entender, estudar e pesquisar também a relação e a importância que a Educação Física possui para o desenvolvimento do processo comunicativo da criança surda.

As questões que surgiram durante a adaptação para crianças surdas de brincadeiras tradicionais foram: as rimas e os jogos com as palavras nessas brincadeiras cantadas podem ser traduzidas para a língua de sinais? Sabemos que as crianças ouvintes têm rico repertório de cantigas e brincadeiras cantadas, o que contribui e muito para o desenvolvimento da linguagem verbal. E as crianças surdas? Como elas podem se beneficiar desse recurso lúdico para o desenvolvimento da língua de sinais? Partimos do pressuposto de que é possível adaptar brincadeiras tradicionalmente associadas à infância para a língua de sinais e os estudos recentes sobre a poesia nos SLAM nos deram algumas pistas. Abrahão (2020) analisa como os surdos, ao declamarem poesias, utilizam gestos para marcar o ritmo, o que serviu de pistas sobre como adaptar as brincadeiras cantadas para as crianças surdas:

Ritmo e métrica são características estéticas que trazem uma marcação de tempo para as produções poéticas. O ritmo é um movimento coordenado, uma repetição de intervalos regulares ou irregulares produzidos por alguma parte do corpo, podendo ser marcado por um pé batendo no chão, um movimento de cabeça ou intervalos regulares na sinalização (ABRAHÃO, 2020, p. 40). 


\section{RevistAleph}

O estímulo gerado pelo ritmo e pela métrica, configuram característica marcante do brinquedo cantado e como se pode inferir, existe relevância na roda de histórias. Sendo de grande auxílio no desenvolvimento das crianças, inclusive daquelas que são surdas. Surge então, uma inquietação: se o brinquedo cantado é importante para o desenvolvimento cognitivo e emocional de toda criança, como proporcionar essa brincadeira para a criança surda?

Para preparar as crianças para entrarem na brincadeira, foram considerados alguns princípios que serão apresentados adiante, adaptados a partir do estudo dos 15 princípios da proposta de leitura compartilhada de Gallaudet. Foi intenção correlacionar as brincadeiras com a proposta de contar histórias, uma vez que a leitura compartilhada vem sendo muito estudada no campo da educação de surdos.

A metodologia do material proposto foi desenvolvida e resultou no projeto dos 7 princípios básicos para adaptações de jogos e brincadeiras na educação física inclusiva, contendo estratégias significativas e uso da língua de sinais, com objetivo de facilitação e adaptação das crianças surdas. Os princípios dizem respeito à valorização de alguns aspectos tais como: 1- Conhecimento Prévio, 2- Ensinamento de novos conteúdos, 3Produção de material; 4-utilização dos materiais, 5-apresentação de jogos e brincadeiras adaptadas, 6- prática dos jogos ou brincadeiras adaptadas e 7- registro e avaliação.

Ao adaptar a brincadeira cantada "Minha Boneca de Lata" alguns desses princípios foram observados. Basicamente, para avaliar o conhecimento prévio das crianças, o professor pode realizar dinâmicas em grupo que abordem as partes do corpo humano, a fim de perceber se elas conhecem seus corpos, suas nomenclaturas, bem como os respectivos sinais para então introduzir aqueles que elas ainda não conheçam e possam de fato entrar na brincadeira. A dinâmica propõem que a criança vá apontando as partes do corpo da boneca de lata que precisam ser consertados. Como leva um tempo para o conserto imaginário, o professor precisa introduzir também a noção de tempo.

Uma forma interessante de iniciar a brincadeira é com a Libração da história da "boneca de lata", assim as relações sociais e afetivas entram na brincadeira. A boneca 


\section{RevistAleph}

pode ser feita de sucata (Figura 4), dando início a atividades de confecção desse e de outros brinquedos. Para avaliar o conhecimento prévio das crianças, o professor realizará dinâmicas em grupo, a fim de perceber seus conhecimentos sobre as partes do corpo e os sinais de Libras correspondentes.

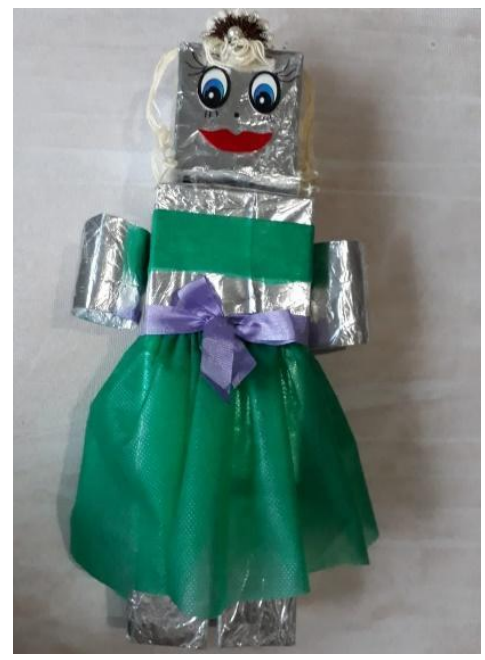

Fonte: Propriedade dos autores.

É importante também observar como as crianças percebem a rotina da educação infantil, seus tempos, o antes e o depois, mostrar o relógio, contar o tempo com ampulheta, lembrar da duração do tempo do lanche, da hora de da entrada e saída, associar o relógio a duração do tempo em horas para tais atividades. Mostrar os sinais das horas em Libras (Figura 5), observando o que os alunos já conhecem. No processo de observar os conhecimentos prévios das crianças e introduzir novos conhecimentos, materiais são produzidos para serem utilizados antes, durante e depois das brincadeiras, para que as crianças se familiarizem com suas regras e dinâmicas. A língua de sinais está sempre presente, mas as experiências resgatadas durante os 7 princípios e as brincadeiras em si, norteiam o trabalho pedagógico.

Figura 5. Relógio

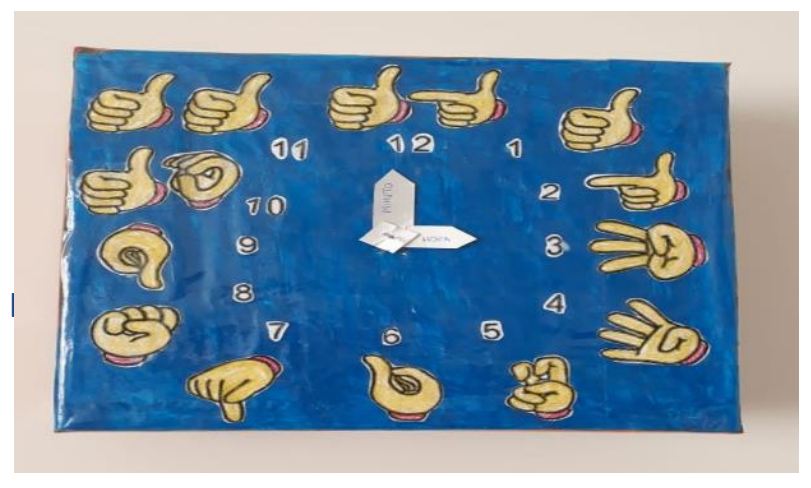




\section{RevistAleph}

Fonte: Propriedade dos autores.

As estratégias apontadas (Libração de histórias, vídeos em Libras, brincadeiras cantadas e a criança como protagonista) são frutos de uma pesquisa de ensino voltada para a educação de surdos em um contexto bilíngue. A funcionalidade dos materiais didáticos construídos para dar visibilidade a alguns elementos centrais foi vivenciada na prática do professor, que percebeu a interação da crianças, o prazer delas em se colocarem na posição de produtoras de conteúdo e as aprendizagens comunicacionais desenvolvidas através das brincadeiras, dos jogos, do conto e reconto, do manuseio dos bonecos e da troca entre os pares.

\section{Considerações finais}

Sabemos que na realidade em que vivemos são minoria os professores fluentes em língua de sinais para o trabalho com alunos surdos, em sua maioria os docentes estão em busca de um caminho para se aprimorarem. Enquanto essa realidade está em percurso de mudança, os alunos continuam nas salas de aula e precisam ser atendidos em suas especificidades linguísticas, emocionais, sociais e afetivas. Não desvalorizamos ou negamos a importância do professor bilíngue - Libras/Português - inclusive ressaltamos a necessidade em tê-lo, mas buscamos apresentar ferramentas eficazes para a interação entre discente surdo e docente ouvinte que extrapolam os aspectos linguísticos e contemplam o indivíduo como um todo, percebendo a importância de uso de diferentes artefatos como estratégias e recursos para tornar as relações entre as crianças e o conhecimento mais enriquecida. É evidente que os professores devem aprimorar o uso da língua de sinais - e como destacamos, tornarem-se bilíngues para atender a legislação prevista pelo Decreto 10.502 de 2020 - mas é importante resgatar também seu lado artesão e criar recursos para tornar a relação de ensino aprendizagem mais lúdica, prazerosa e significativa. 


\section{RevistAleph}

Os princípios da leitura compartilhada nortearam o planejamento destas atividades para crianças surdas. Muitas adaptações podem e foram realizadas, mas o aspecto principal dos princípios que não pode ser abandonado é a centralidade do interesse da criança surda. Considerar a criança e sua produção de sentidos, dar subsídios para que compreenda as propostas, seguir de acordo com o desejo dela, vem ao encontro do que é proposto como diretriz para o currículo da educação infantil. As interações e brincadeiras das crianças são manifestações do seu desejo e cabe ao professor construir materiais e estratégias para ampliar seu repertório de experiências. Nesse contexto, as crianças ampliam seu arcabouço de sinais, sentindo-se valorizadas.

O desenvolvimento da expressão corporal mostrou-se relevante para o surdo em qualquer idade, mas principalmente quando na infância. Pois é a partir da estimulação e do desenvolvimento recebido na infância, que a criança surda terá maiores possibilidades de comunicação, interação e convivência social, assim como de sua realização pessoal.

Muito ainda deve ser estudado a respeito das estratégias dos professores ouvintes para a educação de crianças surdas. Demonstramos os resultados que obtivemos ao interagir com as crianças através de brincadeiras e histórias oriundas da cultura ouvinte, porém adaptadas para o contexto da surdez. Reconhecer o repertório de brincadeiras e de histórias advindas da cultura surda também é fundamental. No entanto, professoras ouvintes têm sua bagagem cultural e é legítimo que queiram oferecer às crianças experiências que fazem parte do seu repertório afetivo. Esse percurso revela adaptações, afetividades, gestos e acolhimentos.

\section{Referências}

ABRAHÃO, B. F. Poesia contemporânea em línguas de sinais e sua influência na sociedade. IN: INES, Revista Espaço, no 53, jan-jun. Rio de Janeiro 2020, pp. 37-50.

BAKHTIN, M. M., VOLOSHINOV, V. N. Discurso na vida e discurso na arte (sobre a poética sociológica). Trad. de Carlos Alberto Faraco e Cristóvão Tezza [para fins didáticos]. Versão da língua inglesa de I. R. Titunik a partir do original russo, 1926.

BRASIL. Decreto no 10.502, de 30 de setembro de 2020. Brasília, 30 de setembro de 2020. Disponível em: http://www.planalto.gov.br/ccivil_03/_ato20192022/2020/decreto/D10502.htm . Acesso em: 08/10/2020. 


\section{RevistAleph}

BRASIL. Ministério da Educação. Secretaria de Educação Básica. Diretrizes curriculares nacionais para a educação infantil / Secretaria de Educação Básica. - Brasília : MEC, SEB, 2010.

CAMPELLO, A. R. e S. Pedagogia visual na educação dos surdos-mudos. Tese apresentada ao Programa de Pós-Graduação de Educação da Universidade Federal de Santa Catarina como requisito para a obtenção do título de Doutorado de Educação, 2008, pp 166.

DELMAR, A. S. M. Conto e reconto de histórias na Educação Infantil: o uso de estratégias visuais no letramento de crianças surdas. Rio de Janeiro. Julho, 2016. Disponível em: <http://www.ines.gov.br/seer/index.php/revista-espaco/article/view/320/349> Acesso em: $27 / 08 / 2020$

KARNOPP, L. e QUADROS, R. M. de. Educação Infantil para surdos. In.: ROMAN, Eurilda Dias; STEYER, Vivian Edit. (Org.). A criança de $\mathbf{0}$ a $\mathbf{6}$ e a educação infantil: um retrato multifacetado. Canoas 2001, p $214-230$

LEBEDEFF, T. B. Alternativas de letramento para crianças surdas: uma discussão sobre o Shared Reading Program. In: REUNIÃO ANUAL DA ANPED, 30., 2007, Caxambu. Anais... Caxambu: ANPED, 2007. p. 1-15. http://30reuniao.anped.org.br/trabalhos/GT15-3727--Int.pdf MACHADO, A. M. O domador de monstros. Ilustradora: Suppa. São Paulo: FDT, 2003. Coleção conta de novo.

MOURÃO, C. H. N. Literatura Surda: experiências das mãos literárias. Tese de doutorado. Universidade Federal do Rio Grande do Sul. Porto Alegre. 2016. Disponível em: < http://www.ufrgs.br/ufrgs/inicial/coringa/repositorio-digital> Acesso em: 15/07/2020.

PIMENTEL, C. As crianças e os livros. Revista Contemporânea de Educação, N 11 janeiro/julho de 2011.

TAVEIRA, C. C.. Por uma didática da invenção surda: prática pedagógica nas escolas-piloto de educação bilíngue no município do Rio de Janeiro / Cristiane Correia Taveira; orientadora: Vera Maria Ferrão Candau. - 2014. 